\title{
Expanded Endoscopic Transsphenoidal Resection of Tuberculum Sella Meningioma Invading the Optic Canal
}

\author{
Georgios Klironomos ${ }^{1}$ Margherita Bruni ${ }^{1} \quad$ Amir R. Dehdashti ${ }^{1}$ \\ ${ }^{1}$ Department of Neurosurgery, Hofstra Northwell School of Medicine, \\ North shore University Hospital, Manhasset, New York, United States \\ J Neurol Surg B 2018;79(suppl S3):S267-S268. \\ Address for correspondence Amir R. Dehdashti, MD, Department of \\ Neurosurgery, Hofstra Northwell School of Medicine, North shore \\ University Hospital, 300 Community Drive, Manhasset, NY, 11030, \\ United States (e-mail: adehdashti@northwell.edu).
}

\begin{abstract}
Keywords

- expanded transsphenoidal

- endoscopic

- vision compromise

- optic canal invasion

A 61-year-old male patient presented with recurrent malignant meningioma involving the left optic canal and decreased vision from the left eye. The patient had undergone orbital exenteration on the right 2 years ago. The decision to treat the patient was made based on the significant vision deterioration and rapid tumor growth. Endoscopic transsphenoidal approach considered the most suitable route due to the inferomedial invasion of the optic canal. Gross total removal was achieved and the patient's vision improved postoperatively. The patient developed hydrocephalus 4 weeks postoperatively and cerebrospinal fluid (CSF) leak. Ventriculoperitoneal shunt placement corrected both hydrocephalus and CSF leak.

The link to the video can be found at: https://youtu.be/2cOF0pf5gAk.
\end{abstract}

Conflict of Interest

None.

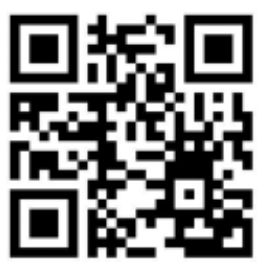

www.thieme.com/skullbasevideos

www.thieme.com/jnlsbvideos

received

October 15, 2017

accepted

December 14, 2017

published online

February 16, 2018

DOI https://doi.org/

10.1055/s-0038-1625944.

ISSN 2193-6331.
๑) 2018 Georg Thieme Verlag KG
Stuttgart · New York

License terms

(c) $(1) \ominus$ (\$) 


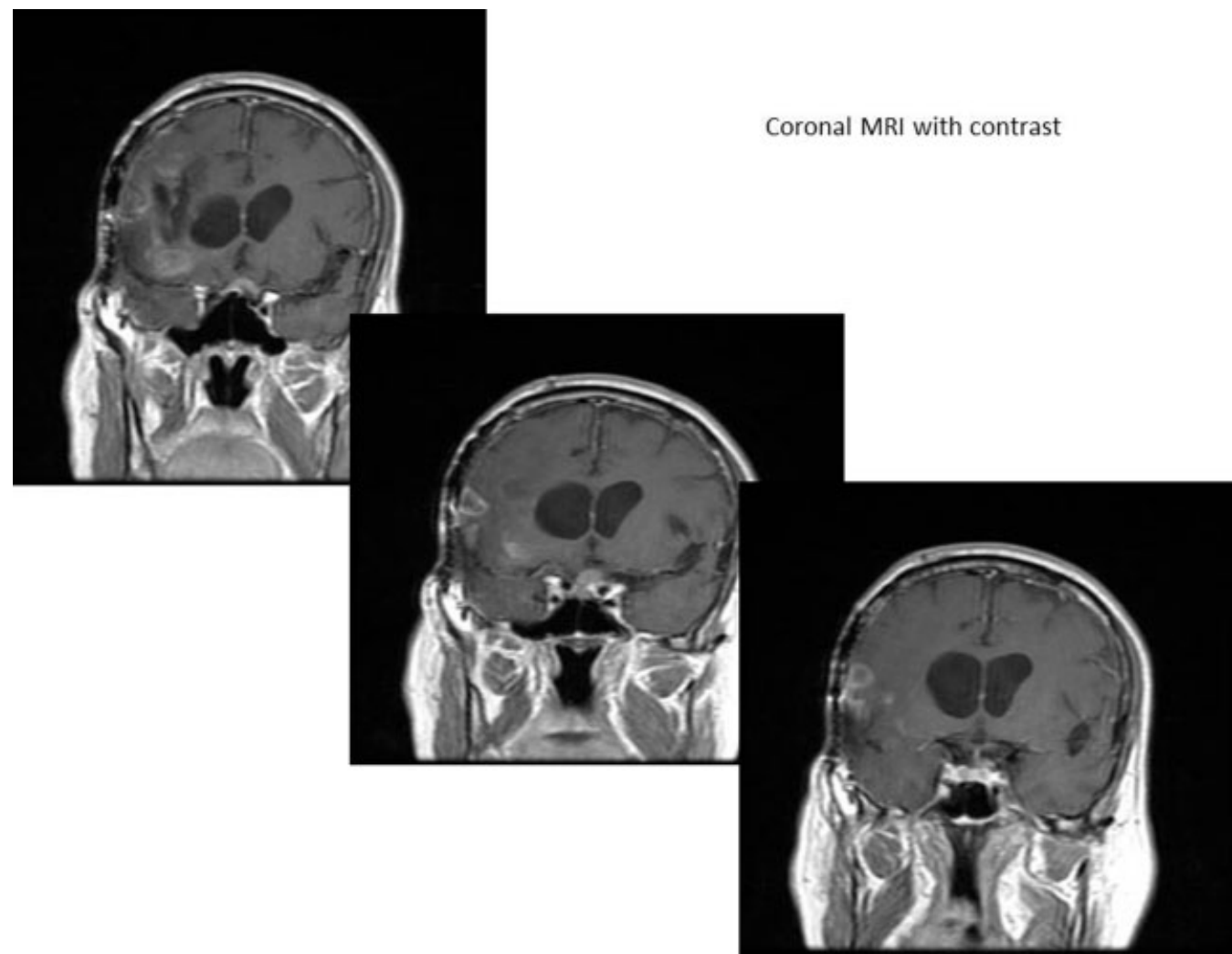

Fig. 1 Pre-op magnetic resonance imaging showing invasion of the left optic canal.

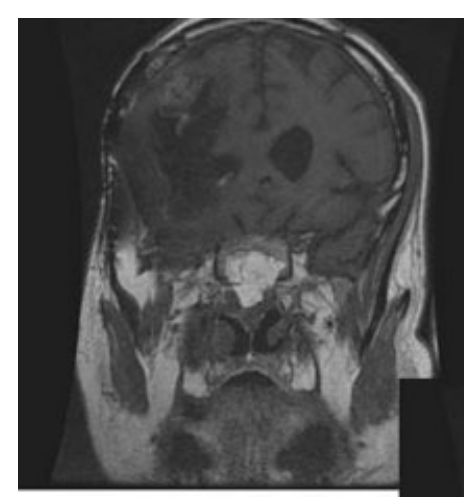

\section{Post op MRI}

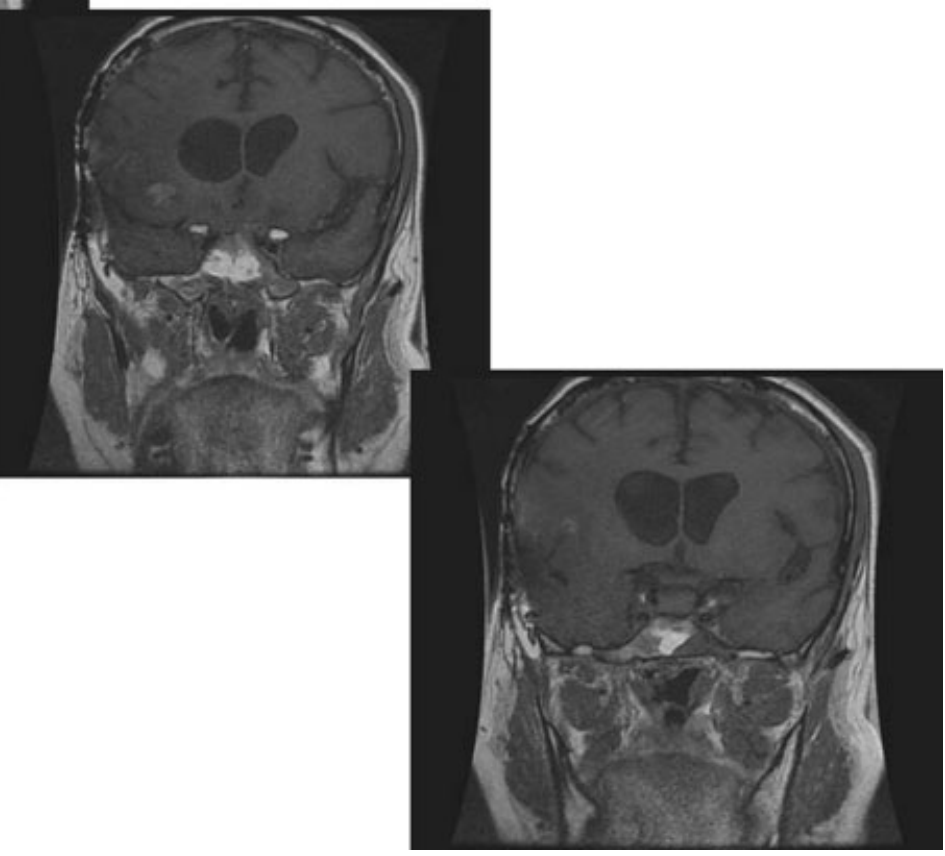

Fig. 2 Post-op magnetic resonance imaging showing complete tumor removal. 